\title{
The effect of home storage conditions and packaging materials on the quality of frozen green beans
}

\author{
R.C. Martins, M.G. Almeida, C.L.M. Silva* \\ Escola Superior de Biotecnologia, Universidade Católica Portuguesa, Rua Dr. António Bernardino de Almeida, $4200-072$ Porto, Portugal
}

\begin{abstract}
Home storage is the final step of the frozen foods distribution chain, and little is known on how it affects the products quality. The present research describes frozen green beans (Phaseolus vulgaris, L.) quality retention profile during the recommended 'star marking' system dates, at the storage temperatures of $+5,-6,-12$ and $-18{ }^{\circ} \mathrm{C}$ (along $1,4,14$ and 60 days, respectively).

The quality profile was assessed by a simulation system. Simulations were set by a response surface methodology to access the effect of different packaging materials (thermal conductivities and thickness), surface heat transfer coefficient, and refrigerator dynamics (effect of refrigeration cycles at the different storage temperatures) on the average retentions of Ascorbic Acid, total vitamin $\mathrm{C}$, colour and flavour.

Green beans quality losses along frozen storage are significantly influenced by temperature, refrigerator dynamics and kinetic properties. Quality is also highly dependent on packaging materials thermal insulation (e.g. at temperatures above the melting point). Temperature cycles inside frozen chambers have a long term effect, and at the higher storage temperatures (e.g. $T>-6{ }^{\circ} \mathrm{C}$ ) are detrimental to frozen green beans quality after shorter periods.
\end{abstract}

\section{Qualité des haricots surgelés: impact de la conservation chez le consommateur ainsi que les matériaux d'emballage}

Mots-clés: Produit surgelé; Haricot vert; Modélisation; Transfert de Chaleur; Emballage; Durée de conservation; Réfrigérateur Domestique

\section{Introduction}

Green beans (Phaseolus vulgaris, L.) are among the most important vegetables produced in Portugal. They are generally harvested seasonally, and the outdoor varieties

\footnotetext{
* Corresponding author. Tel.: +351-22-5580058; fax: +351-225090351.

E-mail addresses: crislui@esb.ucp.pt (C.L.M. Silva),r.m.c.m@ clix.pt (R.C. Martins), miguel@datindex.com (M.G. Almeida).
}

are excellent in nutritional value (high fibber content, starch and water soluble vitamins) and sensory parameters, such as colour, texture and flavour. Frozen green beans contribute to a well balanced diet all over the year, presenting nutritional advantages against human illness, and therefore, are important both in dietary and economical terms.

Frozen storage is well known for its excellence in preserving nutritional and sensory quality. Nevertheless, significant nutritional and sensory losses do occur at low temperatures. Isothermal storage of green beans, at the 


\begin{tabular}{|c|c|}
\hline \multicolumn{2}{|c|}{ Nomenclature } \\
\hline$\alpha$ & confidence level \\
\hline$\beta_{i}$ & quadratic polynomial constant \\
\hline$\lambda$ & thermal conductivity $\left(\mathrm{W} \mathrm{m}^{-1} \mathrm{~K}^{-1}\right.$ ) \\
\hline $\mathbf{A}$ & $T_{0}$, coded factor analysis $\left({ }^{\circ} \mathrm{C}\right)$ \\
\hline B & $h$, coded factor analysis $\left(\mathrm{W} \mathrm{m}^{-2} \mathrm{~K}^{-1}\right)$ \\
\hline $\mathbf{C}$ & $\lambda_{\mathrm{p}}$, coded factor analysis $\left(\mathrm{W} \mathrm{m}^{-1} \mathrm{~K}^{-1}\right)$ \\
\hline D & $x_{\mathrm{p}}$, coded factor analysis $(\mathrm{m})$ \\
\hline $\mathbf{Y}$ & quality retention response $(\%)$ \\
\hline$a, b, c, d$ & modified Schwarzberg equation constants \\
\hline & quality retention $(\%)$ at time $t$ \\
\hline$C_{\mathrm{p}}$ & thermal capacity $\left(\mathrm{J} \mathrm{kg}^{-1} \mathrm{~K}^{-1}\right)$ \\
\hline$E a$ & Arrhenius activation energy $\left(\mathrm{kJ} \mathrm{mol}^{-1}\right)$ \\
\hline$h$ & $\begin{array}{l}\text { surface heat transfer coefficient } \\
\left(\mathrm{W} \mathrm{m}^{-2} \mathrm{~K}^{-1}\right)\end{array}$ \\
\hline$k$ & kinetic rate $\left(\right.$ day $\left.^{-1}\right)$ \\
\hline$R$ & universal gas constant $\left(\mathrm{J} \mathrm{mol}^{-1} \mathrm{~K}^{-1}\right)$ \\
\hline$T$ & temperature $\left({ }^{\circ} \mathrm{C}\right.$ or $\left.\mathrm{K}\right)$ \\
\hline$t$ & time (days) \\
\hline TCD & total colour difference \\
\hline & packaging film thickness (m) \\
\hline & ascorbic acid \\
\hline DHAA & dehydro-ascorbic acid \\
\hline \multicolumn{2}{|c|}{ Subscripts } \\
\hline 0 & refers to initial condition \\
\hline$\infty$ & refers to medium temperature \\
\hline eq & refers to equilibrium \\
\hline $\mathrm{f}$ & refers to frozen \\
\hline $\mathrm{H}$ & refers to Hunter \\
\hline & refers to melting \\
\hline $\mathrm{p}$ & refers to packaging material \\
\hline
\end{tabular}

temperatures of $-7,-15$ and $-30{ }^{\circ} \mathrm{C}$, showed that green beans quality parameters, such as ascorbic and dehydroascorbic acids (vitamin C), starch, reducing sugars, colour and texture are especially sensitive during storage $[1,2]$.

Quality loss is not only an important subject from the marketability point of view, but is also a public health concern, as the nutritional value decreases during frozen storage and distribution.

The shelf life of frozen vegetables is currently attributed under the 'Star Marking' system in Portugal. Manufacturers mark the different compartments of the refrigerator according to its temperature. Frozen foods producers use the same system to produce a storage time recommendation for frozen vegetables, according to storage temperature. Table 1 presents the pre-established after-sale dates, generally used for vegetables under the star marking system. Most of these storage time recommendations are based on isothermal conditions; under which most of the information on distribution conditions is assumed and effects on nutritional and sensory quality are neglected. Most of the isothermal studies on quality losses were produced during the timetemperature-tolerance (TTT) project, aiming at establishing shelf-life dates for different storage temperatures. The TTTproject principles are still the basis for storage and distribution conditions of frozen foods [3-5].

The relatively simple approach of the TTT project to quality losses is mainly attributed to the complexity of quality losses throughout the distribution chain. Long storage times and many quality parameters under study are the two major hurdles to develop frozen foods storage studies. Furthermore, the spectrum of temperature responses is difficult to be reproduced under laboratory conditions. Under real conditions, the distribution chain spectrum of temperature exhibits limited predictability, that is, distribution temperatures are chaotic and only predictable under tight control. The TTT simplifies the approach to this problem, by assuming that the spectrum of temperature is possible to be characterised, once adequate temperature control is active in the chain $[6,7]$.

The star marking system is currently applicable to almost any frozen vegetable. However, frozen vegetables quality losses are diverse and very dependent on storage conditions. Important factors, such as the initial temperature, refrigerator dynamics, packaging materials and physical-chemical properties are often neglected when attributing shelf-life dates. Neglecting such important factors, for the sake of simplicity, may have unknown effects on predicted data.

Foods can be considered as complex systems [8], where the necessary amount of information, that is needed to produce a valid shelf-life date, is yet unknown.

Experimental determination of shelf-life becomes difficult as many variables are to be controlled under laboratory conditions. Moreover, important factors and interactions are not controllable during experimentation. Experimental errors, such as spectrum of temperature responses, thermal-physical properties and chemical analysis may lead to misinterpretation. Thus, the experimental evaluation of shelf life and quality losses is yet limited to simple case studies.

Complexity can be recreated into computer models, where many physical-chemical phenomena are simulated, such as heat and mass transfer, quality degradation and microbiological growth. In such models, physical relationships between phenomena and model variables are possible to be controlled. Therefore, these can be analysed, within a

Table 1

Frozen foods star marking system

\begin{tabular}{lll}
\hline Star code & Average temperature & $\begin{array}{l}\text { Remaining shelf life inside } \\
\text { the refrigerator }\end{array}$ \\
\hline Refrigerator & $+5{ }^{\circ} \mathrm{C}$ & 1 day \\
$*$ & $-6^{\circ} \mathrm{C}$ & 4 days \\
$*$ & $-12{ }^{\circ} \mathrm{C}$ & 14 days \\
$* * *$ & $-18{ }^{\circ} \mathrm{C}$ & 60 days \\
\hline
\end{tabular}


theoretical basis, that is not possible throughout experimentation [8].

The main motivation of this research was to computationally access and evaluate the green beans quality profile during the storage inside household refrigerators, aiming at producing detailed information about the different factors that affect quality losses and shelf-life during storage. Therefore, the objectives of this research study were to:

1. Evaluate the impact of refrigerator dynamics on frozen green beans quality retention.

2. Evaluate the impact of different packaging materials and film thickness on frozen green beans quality loss prevention.

\section{Materials and methods}

\section{Computational model}

The finite elements method, using the consistent formulation, was used to model heat transfer, with phase transition, and quality losses across a frozen green beans physical domain [8-10].

Fig. 1 presents the green beans package and the corresponding finite elements mesh. Heat transfer is assumed to occur by convection at the package surface and by conduction inside the package. The air thermal capacity, conductivity and density are held constant throughout the simulation. Parallel computer programs for FEM simulation were written in $\mathrm{C}++[8]$ and let to run on a four node Linux Beowulf Class Cluster [11-13], under the PVM library [14].

Green beans thermal capacity and conductivity were described by a linear model above the freezing point. Below the freezing point, thermal capacity was described by the modified Schwarzberg equation [15] (Eq. (1)) and thermal conductivity by the Schwarzberg equation [16] (Eq. (2)):

$C_{\mathrm{p}}=a+b T+\frac{c}{(d-T)^{2}}$

where $a, b, c$ and $d$ are the modified Schwarzberg equation constants.

$\lambda=\lambda_{\mathrm{f}}+\left(\lambda_{\mathrm{m}}-\lambda_{\mathrm{f}}\right) \frac{\left(T-T_{\mathrm{m}}\right)}{\left(T_{\mathrm{w}}-T_{\mathrm{m}}\right)^{2}}$

where $\lambda_{\mathrm{f}}$ and $\lambda_{\mathrm{m}}$ are the thermal conductivities of green beans completely frozen and at the melting point temperature $\left(T_{\mathrm{m}}\right)$, respectively. $T_{\mathrm{w}}$ is the melting point temperature of pure water.

Quality losses were modelled by first order (Eq. (3)) and fractional conversion (Eq. (4)) kinetics [17], exhibiting Arrhenius behaviour with temperature $[1,2]$.

$c=c_{0} \exp \left(-k_{\text {ref }} \exp \left[-\frac{E a}{R}\left(\frac{1}{T}-\frac{1}{T_{\text {ref }}}\right)\right] \cdot t\right)$
$\frac{c-c_{\text {eq }}}{c_{0}-c_{\text {eq }}}=\exp \left(-k_{\text {ref }} \exp \left[-\frac{E a}{R}\left(\frac{1}{T}-\frac{1}{T_{\text {ref }}}\right)\right] \cdot t\right)$

where $c$ is the quality retention (\%) at time $t, c_{0}$ the initial quality retention (\%), $c_{\text {eq }}$ the equilibrium quality retention $(\%), k_{\text {ref }}$ the kinetic rate $\left(\mathrm{day}^{-1}\right)$ at the reference temperature, $T_{\text {ref }}(\mathrm{K}), E a$ the Arrhenius activation energy $\left(\mathrm{J} \mathrm{mol}^{-1}\right)$ and $R$ the universal gas constant $\left(\mathrm{J} \mathrm{mol}^{-1} \mathrm{~K}^{-1}\right)$

Kinetics were discretized stochastically into the FEM mesh [8]. Quality parameters do not diffuse also inside the green beans mesh, which makes reaction rates space independent, and only dependent on the local temperature and quality retention. The volume average quality retention was calculated for further data analysis.

\section{Temperature cycles inside the refrigerato}

The spectrum of temperature responses inside the refrigerator was modelled by a stable limit cycle $[8,18]$. Thermal fluctuations inside a refrigerator can be regarded mathematically as a stable limit cycle, where temperature is

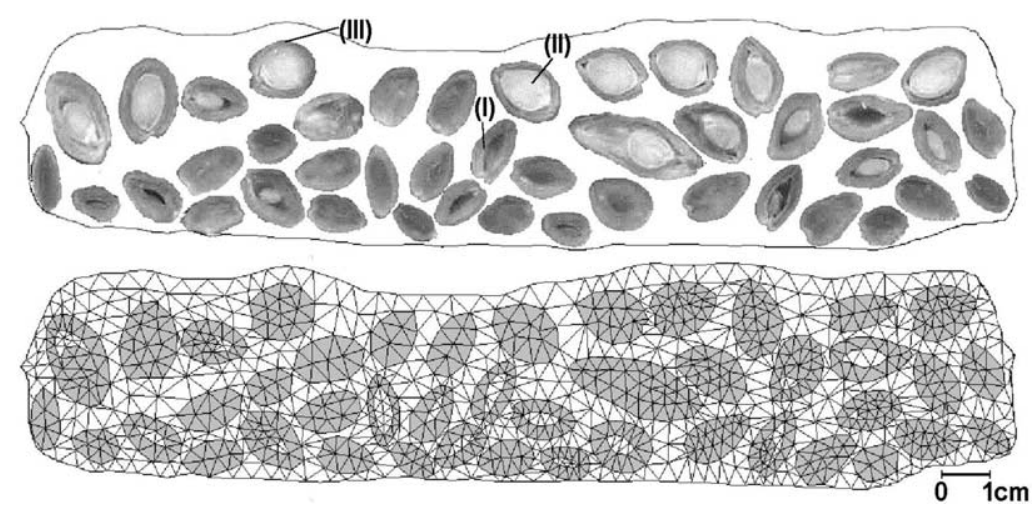

Fig. 1. Axial cut to a frozen green beans package and its FEM mesh, where (I), (II) and (III) are selected nodal points. 
Table 2

Green beans quality losses kinetic parameters

\begin{tabular}{|c|c|c|c|c|}
\hline Quality parameter & $c_{0}$ & $c_{\mathrm{eq}}$ & $k_{\text {ref }}{ }^{\mathrm{a}}\left(\right.$ day $\left.^{-1}\right)$ & $E a\left(\mathrm{~kJ} \mathrm{~mol}^{-1}\right)$ \\
\hline Ascorbic acid (mg $\left.100 \mathrm{~g}^{-1}\right)$ & 146.1 & - & $15.61 \times 10^{-2}$ & 3.86 \\
\hline Vitamin C $\left(\mathrm{mg} 100 \mathrm{~g}^{-1}\right)$ & 146.1 & - & $3.226 \times 10^{-2}$ & 42.01 \\
\hline Chlorophyll a ( $\left.\mathrm{mg} \mathrm{g}^{-1}\right)$ & $4.559 \times 10^{-2}$ & - & $4.793 \times 10^{-2}$ & 48.73 \\
\hline Chlorophyll b ( $\left.\mathrm{mg} \mathrm{g}^{-1}\right)$ & $2.572 \times 10^{-2}$ & - & $4.795 \times 10^{-2}$ & 49.60 \\
\hline$a$-value & -11.931 & -6.329 & $6.600 \times 10^{-3}$ & 103.05 \\
\hline$b$-value & 13.099 & 10.101 & $22.189 \times 10^{-3}$ & 55.33 \\
\hline $\mathrm{TCD}_{\mathrm{H}}$ & 3.745 & 7.486 & $5.999 \times 10^{-3}$ & 106.27 \\
\hline Stress (MPa) & 2.453 & 1.237 & $3.828 \times 10^{-2}$ & 7.11 \\
\hline 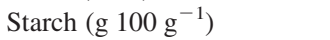 & 8.211 & - & $9.896 \times 10^{-2}$ & 12.33 \\
\hline Flavour $^{\mathrm{b}}(\%)$ & 100 & - & $7.769 \times 10^{-2}$ & 117.00 \\
\hline
\end{tabular}

${ }^{\mathrm{a}} T_{\text {ref }}=-15^{\circ} \mathrm{C}$.

b Data from Ref. [19].

a well-defined observable periodic oscillation, and fluctuates around a central area on a phase diagram. Physically, limit cycles represent the dynamic stationary state of sustained oscillations, which does not depend on initial conditions, but depend exclusively on the system parameters [18].

This kind of physical dynamical behaviour can be described into two phases: (I) when the compressor is turned on and (II) when the compressor is turned off. In each of these two regions, the system's dynamics is described by a linear stochastic differential equation, where the constants are different for different refrigerator's thermostat position [8].

The effect of thermal cycles inside the refrigerator on quality losses was studied by comparing the simulated quality losses with thermal fluctuations against a constant set-point thermostat temperature (isothermal storage and initial temperature at the corresponding star system temperature of $+5,-6,-12$ and $-18{ }^{\circ} \mathrm{C}$ ).

Quality losses were calculated for the following parameters: (i) ascorbic acid (AA); (ii) total vitamin C (ascorbic and dehydro-ascorbic acid contents, AA + DHAA); (iii) chlorophylls a and b; (iv) Colour: Hunter $a$ value, $b$-value and total colour difference, $\mathrm{TCD}_{\mathrm{H}}$; (v) Texture: stress at the failure point; (vi) starch content and (vii) flavour retention (data from Ref. [19]). Quality loss kinetic parameters are presented in Table 2.

\section{Experimental design}

Quality retention was studied as function of the initial temperature, $T_{0}\left({ }^{\circ} \mathrm{C}\right)$, surface heat transfer coefficient, $h$ ( $\mathrm{W} \mathrm{m}{ }^{-2} \mathrm{~K}^{-1}$ ), packaging thermal conductivity, $\lambda_{\mathrm{p}}$ $\left(\mathrm{W} \mathrm{m}^{-1} \mathrm{~K}^{-1}\right.$ ) and packaging film thickness, $x_{\mathrm{p}}(\mathrm{m})$, using a Box-Behnken factorial design [20].

Factorial design maximum and minimum levels are presented in Table 3. The design comprised 29 combinations from the described factors, built in one block. Each of the design combinations was studied for the corresponding 'star system' storage temperatures of +5 , $-6,-12$, and $-18{ }^{\circ} \mathrm{C}$ (Table 1). Data were recorded heuristically at the time intervals: (i) 8,16 and $24 \mathrm{~h}$ at $+5{ }^{\circ} \mathrm{C}$; (ii) $1,2,3$ and 4 days at $-6{ }^{\circ} \mathrm{C}$; (iii) 5,10 and 14 days at $-12{ }^{\circ} \mathrm{C}$; and (iv) $15,30,45$ and 60 days at $-18{ }^{\circ} \mathrm{C}$.

Quality retention (\%) is assumed to be described by a second order polynomial:

$$
\begin{aligned}
\mathbf{Y}= & \beta_{0}+\beta_{1} \mathbf{A}+\beta_{2} \mathbf{B}+\beta_{3} \mathbf{C}+\beta_{4} \mathbf{D}+\beta_{12} \mathbf{A} \mathbf{B}+\beta_{13} \\
& \mathbf{A C}+\beta_{14} \mathbf{A D}+\beta_{23} \mathbf{B C}+\beta_{24} \mathbf{B D}+\beta_{34} \mathbf{C D}+\beta_{11} \\
& \mathbf{A}^{2}+\beta_{22} \mathbf{B}^{2}+\beta_{33} \mathbf{C}^{2}+\beta_{44} \mathbf{D}^{2}
\end{aligned}
$$

where $\mathbf{A}, \mathbf{B}, \mathbf{C}$, and $\mathbf{D}$ are the coded polynomial variables for the initial temperature $\left(T_{0}\right)$, surface heat transfer coefficient $(h)$, thermal conductivity $\left(\lambda_{\mathrm{p}}\right)$ and packaging film thickness $\left(x_{\mathrm{p}}\right)$, respectively. $\mathbf{Y}$ is the quality retention $(\%)$ response surface, and $\beta_{i}$ the adjusted polynomial coefficients.

The polynomial coefficients $\beta_{i}$ of Eq. (5) were determined using the software Design Expert (version 4.0.2) [21]. Residuals adequacy were analysed for outlayers, randomness and tested for normality. The statistical significance of factors and their interactions was performed by computing the studentized effect $\left(\beta_{i} / s\left\{\beta_{i}\right\}\right)$ at $5 \%$ confidence level (double sided $T$-test, $t_{0.975 ; 14}=2.145$ ). Model prediction adequacy and fit was accessed by the ANOVA, one factor without replication $(\alpha=0.05)$.

Table 3

Response surface design: factors and factor levels

\begin{tabular}{lcc}
\hline Factor & \multicolumn{2}{l}{ Level } \\
\cline { 2 - 3 } & Min & Max \\
\hline A-initial temperature, $\left({ }^{\circ} \mathrm{C}\right)$ & -30 & -5 \\
B-surface heat transfer convection & 6 & 12 \\
$\quad$ coefficient, $\left(\mathrm{W} \mathrm{m}^{-2} \mathrm{~K}^{-1}\right)$ & & \\
C-thermal conductivity, $\left(\mathrm{W} \mathrm{m}{ }^{-1} \mathrm{~K}^{-1}\right)$ & 0.02 & 0.15 \\
$\mathrm{D}-$ packaging film thickness, $(\mathrm{m})$ & 0.0002 & 0.003 \\
\hline
\end{tabular}




\section{Results and discussion}

\section{Effect of thermal-cycles}

The spectrum of temperature responses is presented for selected nodal temperatures at +5 and $-18{ }^{\circ} \mathrm{C}$ in Fig. 2.

It is possible to observe that thermal insulation affects significantly the thawing time at $+5^{\circ} \mathrm{C}$ (Fig. 2(a) and (b)). Thermal insulating packaging materials may provide insulation to prevent a green beans package from thawing during 10-15 h (Fig. 2(a)). Normal packages, which use low insulating materials, rely on the trapped air at the head space and air voids to provide insulation. This effect is observed as $3-7 \mathrm{~h}$ of thawing time for the same green beans bulk, under the minimal thermal insulation (Fig. 2(b) node I).

Air inside green beans package has a high thermal diffusivity, compared to green beans, and therefore its temperature increases very rapidly. The air voids temperature is always near the thermal equilibrium, between the

(a)

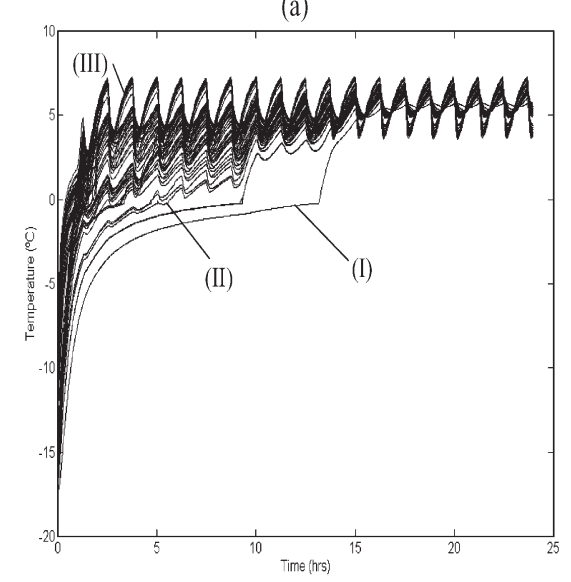

(c)

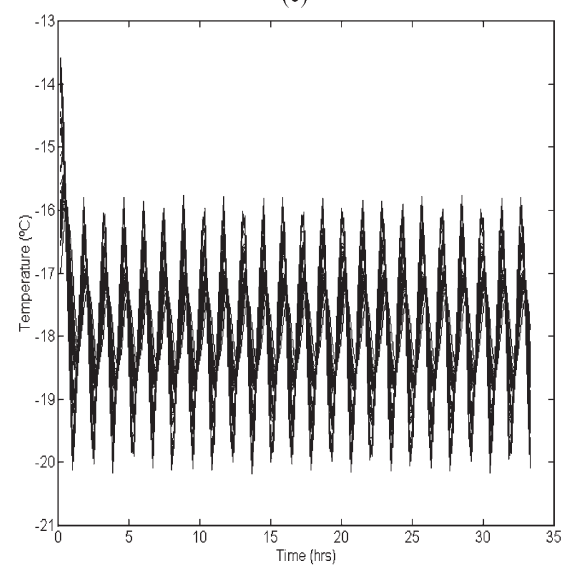

medium temperature and the green beans. Therefore, air voids fail to prevent the refrigerator thermal cycles and temperature fluctuations effects, which can cross the bulk rapidly (especially inside green beans). Trapped air contributes, however, for an effective bulk thermal insulation, if significant temperature gradients are imposed, such as the case of a temperature abuse.

The high thermal capacity of frozen green beans, especially near the melting temperature, reduces the thermal fluctuation throughout the bulk, by absorbing latent heat of fusion. Thus, a thermocouple inserted in any air void would record thermal fluctuations, but one inside green beans would exhibit smaller temperature oscillations. Similarly, the temperature near the green beans surface is also sensitive to temperature oscillations, due to thermal cycles (e.g. node II in Fig. 2(a) and (b)). Furthermore, thermal oscillations are greater for green beans near the package surface (see Fig. 2(a) and (b), at the nodal positions (I), (II) and (III) in Fig. 1).

Furthermore, thermal energy transferred between green beans by conduction is negligible, because the surface

(b)

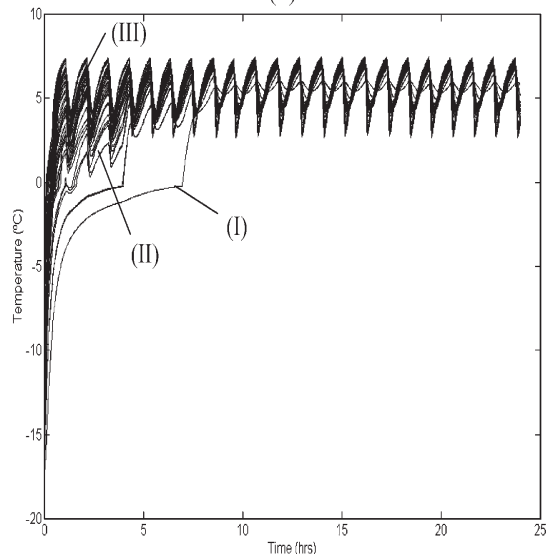

(d)

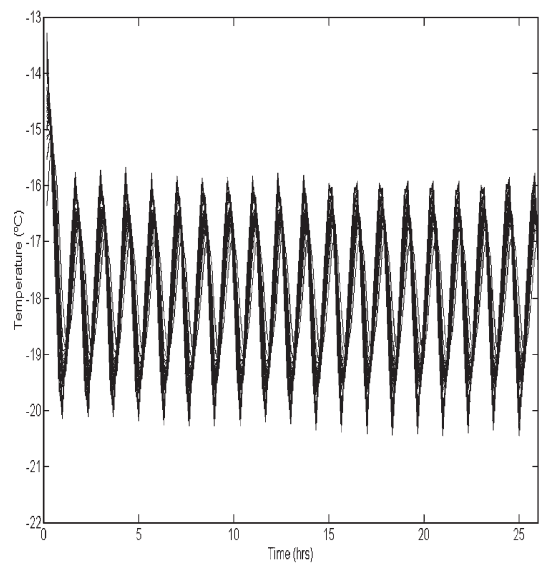

Fig. 2. Time-temperature spectrum for selected nodal positions: (a) max thermal insulation at $+5^{\circ} \mathrm{C}$, where (I), (II) and (III) are the temperatures of the selected nodal points presented in Fig. 1; (b) min thermal insulation at $+5^{\circ} \mathrm{C}$, where (I), (II) and (III) are the temperatures of the selected nodal points presented in Fig. 1 ; (c) max thermal insulation at $-18{ }^{\circ} \mathrm{C}$ and (d) min thermal insulation at $-18^{\circ} \mathrm{C}$. 
contact area between beans is extremely small, when compared with the total surface area exposed to air voids inside the package (see Fig. 1).

Temperature fluctuations tend to accelerate quality losses. A previous study has shown that thermal fluctuations inside refrigerators should be accounted for during isothermal kinetic determinations. Isothermal studies can only be considered 'isothermal', once this condition is statistically proved [22].

Thermal cycles present distinct dynamic properties at the different thermostat setpoints. Cycles are longer in the off position at higher storage temperatures, due to two main reasons: (i) lower temperature difference between the refrigerator and the environmental temperature, and (ii) higher product thermal capacitance. Furthermore, at high temperatures the refrigerator air temperature decreases very rapidly as the compressor is turned on, while it increases more and more slowly, due to latent heat effect, when the compressor is turned off (see Fig. 2(a) and (b)). The slowing rate of increase before the compressor cuts back in, causes the product to spend more time above the set point than below it, which has a negative effect on quality retention.

At lower temperatures, thermal cycles exhibit a different behaviour. Most home refrigerators are today built for low energy consumption. Thus, refrigerators have small compressors, and at low temperatures the refrigeration cycle is mostly active at all times to compensate temperature gradients. Due to the higher thermal gradient and limited capacity of the compressor, the temperature inside the refrigerator takes longer times to attain the lower thermostat level. Consequently, cycles are spent longer times at temperatures below the set point temperature.

The effect of thermal cycles inside the refrigerator was studied by comparing the simulated quality losses with refrigeration cycles against a constant isothermal storage quality loss.

Green beans thermal capacity decreases and the thermal conductivity increases as the storage temperature is lowered. As thermal energy absorbancy is decreased, temperature inside the green beans package is more susceptible to the refrigerator fluctuations at the lower temperatures. The effect is observable by sequencing Fig. 2(a)-(d).

Average quality retention values are presented in Table 4, for simulated data and expected values under constant storage temperature conditions. It is possible to conclude from this table that the quality retention of reactions with low Arrhenius activation energy $(E a)$, such as ascorbic acid, total vitamin $\mathrm{C}$, starch and stress at the failure point and chlorophylls, are influenced to a small extent due to thermal fluctuations $(<1 \%)$, during the recommended storage time.

Retentions at $+5^{\circ} \mathrm{C}$ are higher than the isothermal conditions, due to the influence of the initial storage temperature $\left(-30{ }^{\circ} \mathrm{C}<T_{0}<-5{ }^{\circ} \mathrm{C}\right)$, and the time spent at lower temperatures than $+5^{\circ} \mathrm{C}$, including the green beans phase transition. Such effect is observable by comparing the values (I) - isothermal storage, and (II) - storage under refrigeration cycles, presented in Table 4 at $+5{ }^{\circ} \mathrm{C}$.

Quality parameters with high $E a$, such as $\mathrm{TCD}_{\mathrm{H}}$ and flavour, exhibit a significant influence from thermal fluctuations, where the thermal fluctuations effect is much greater than the assumed constant temperature. However, $\mathrm{TCD}_{\mathrm{H}}$ and flavour degradations are minimised at $+5{ }^{\circ} \mathrm{C}$, due to the low initial temperature and latent heat of fusion.

$\mathrm{TCD}_{\mathrm{H}}$ retention is enhanced at low temperature. The effect of thermal fluctuations at $-18{ }^{\circ} \mathrm{C}$ increases the retention above the expected from the isothermal conditions, due to

Table 4

Average quality retention (\%): (I) assuming isothermal storage conditions at the thermostat set-point temperature and (II) Green beans package simulation under refrigeration cycles

\begin{tabular}{|c|c|c|c|c|c|c|c|c|}
\hline \multirow[t]{3}{*}{ Quality parameter (\%) } & \multicolumn{8}{|c|}{ Temperature } \\
\hline & \multicolumn{2}{|c|}{$+5^{\circ} \mathrm{C}^{\mathrm{a}}$} & \multicolumn{2}{|c|}{$-6^{\circ} \mathrm{C}^{\mathrm{b}}$} & \multicolumn{2}{|c|}{$-12{ }^{\circ} \mathrm{C}^{\mathrm{c}}$} & \multicolumn{2}{|c|}{$-18^{\circ} \mathrm{C}^{\mathrm{d}}$} \\
\hline & I & II & I & II & I & II & I & II \\
\hline Ascorbic acid & 83.72 & 83.81 & 51.51 & 51.47 & 10.74 & 10.72 & 0.01 & 0.01 \\
\hline Total vit. C & 87.65 & 88.11 & 77.91 & 77.54 & 56.81 & 56.48 & 21.49 & 21.23 \\
\hline Chlorophyll a & 78.30 & 79.08 & 66.23 & 65.59 & 41.85 & 41.38 & 11.06 & 10.82 \\
\hline Chlorophyll b & 77.68 & 78.31 & 65.85 & 65.04 & 41.67 & 41.13 & 11.16 & 10.97 \\
\hline Hunter $a$-value & 91.17 & 91.54 & 94.14 & 93.83 & 93.04 & 92.80 & 90.53 & 90.86 \\
\hline Hunter $b$-value & 96.98 & 97.11 & 95.64 & 95.53 & 92.19 & 92.09 & 85.67 & 85.58 \\
\hline $\mathrm{TCD}_{\mathrm{H}}$ & 0.66 & 18.22 & 2.27 & 12.62 & 8.14 & 14.27 & 30.31 & 18.76 \\
\hline Stress & 97.65 & 97.68 & 92.20 & 92.21 & 78.84 & 78.90 & 55.87 & 56.03 \\
\hline Starch & 86.12 & 86.21 & 61.86 & 61.64 & 22.76 & 22.66 & 0.39 & 0.38 \\
\hline Flavour & 10.67 & 12.30 & 32.81 & 30.33 & 31.27 & 29.63 & 24.58 & 23.22 \\
\hline
\end{tabular}

\footnotetext{
${ }^{a}$ At $24 \mathrm{~h}$ of storage time.

b At the fourth day of storage time.

c At the 14th day of storage time.

d At the 60th day of storage time.
} 
(a)

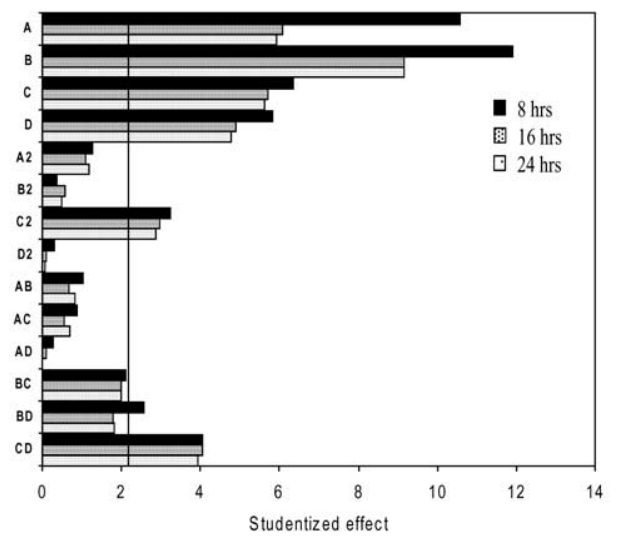

(c)

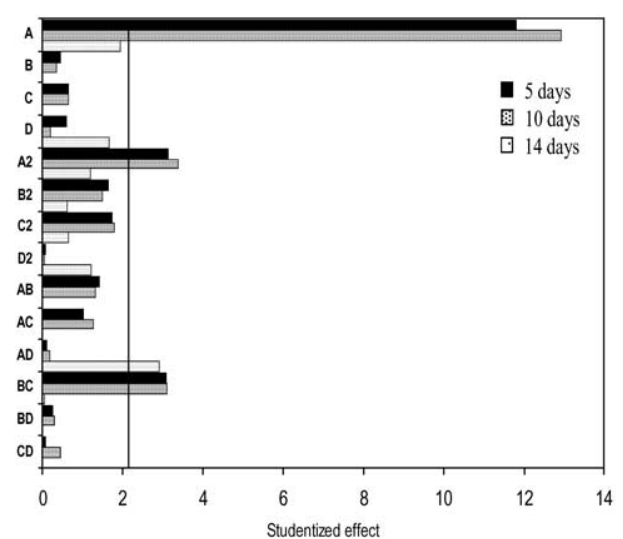

(b)

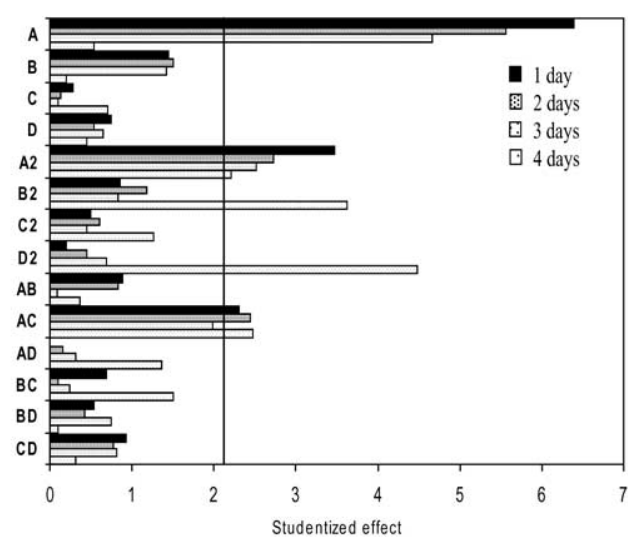

(d)

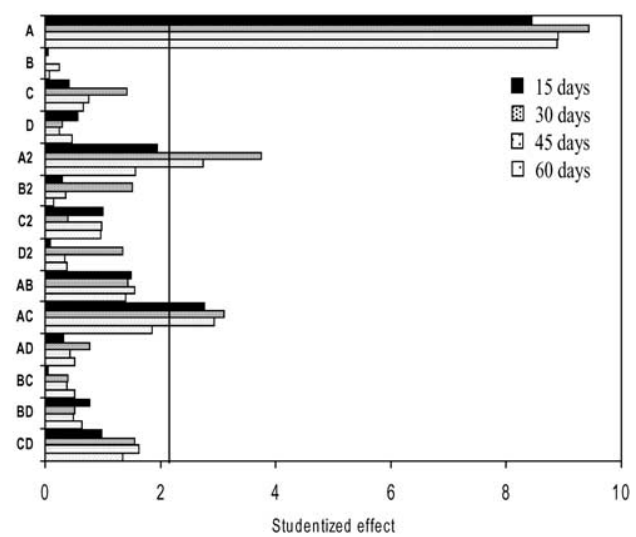

Fig. 3. Studentized effects on AA retention at (a) +5 , (b) -6 , (c) -12 and (d) $-18{ }^{\circ} \mathrm{C}$. A-initial temperature $\left(T_{0}\right)$; B-surface heat transfer coefficient $(h)$; C-packaging thermal conductivity $\left(\lambda_{\mathrm{p}}\right)$; and D-packaging thickness $\left(x_{\mathrm{p}}\right)$.

the nature of thermal cycles, with long exposures to temperatures below the set-point. However, the average retentions of $\mathrm{TCD}_{\mathrm{H}}$ presented in Table 4 are below the isothermal storage. This is only because the initial temperature is for most simulation cases greater than $-18{ }^{\circ} \mathrm{C}$, affecting $\mathrm{TCD}_{\mathrm{H}}$ retention right in the start of the simulation. The initial temperature is a more important factor than thermal fluctuations at low storage temperatures.

Flavour is also well retained at $+5{ }^{\circ} \mathrm{C}$, due to the low initial temperature. Flavour retention is also influenced by thermal cycles in average terms $(1-2.5 \%)$ at the storage temperatures of $-6,-12$ and $-18{ }^{\circ} \mathrm{C}$.

The results emphasise that the thermal fluctuations effect on quality losses are dependent on the storage temperature and its dynamics, and kinetic properties, such as kinetic rates and the Arrhenius activation energy. Thermal fluctuations are generally detrimental at the higher storage temperatures, by accelerating quality losses. These thermal fluctuations effects are even more significant for longer storage periods [1] than the 'star marking' period (Table 1).

The Arrhenius exponential behaviour of most quality degradation reactions potentiates the effect of thermal fluctuations, especially if $E a$ is high (e.g. $E a>80 \mathrm{~kJ} \mathrm{~mol}^{-1}$ ).

As reaction rates increase exponentially with temperature, reaction rates differences are larger at the higher storage temperatures. Thus, long storage times in the off thermostat position potentiates quality losses reactions. At lower temperatures, the kinetic rates tend to stabilise. Therefore, the effect of thermal fluctuations is not as evident as at higher storage temperatures.

Results emphasise that the effect of the refrigerator thermal cycles dynamics is strongly dependent on the storage temperature. The refrigerator dynamics at different temperatures, kinetics (kinetic rates and Arrhenius activation energy), as well as the heat transfer phenomena are significant factors that contribute to quality losses and shelf-life predictions.

\section{Response surface analysis}

The response surface analysis was split into two groups, according to the kinetics temperature sensitivity to 
(a)

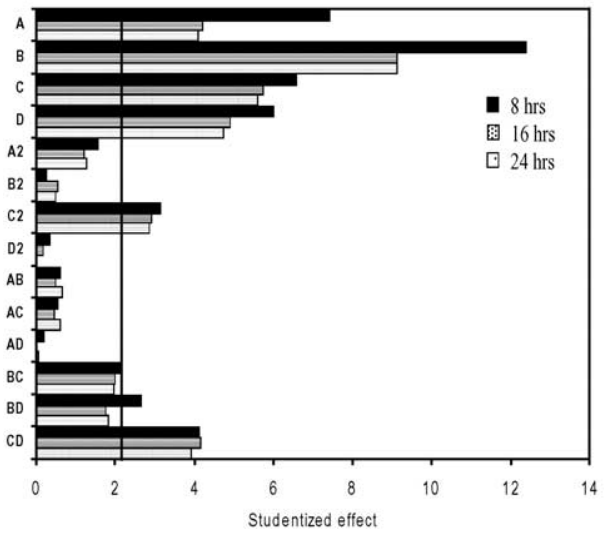

(c)

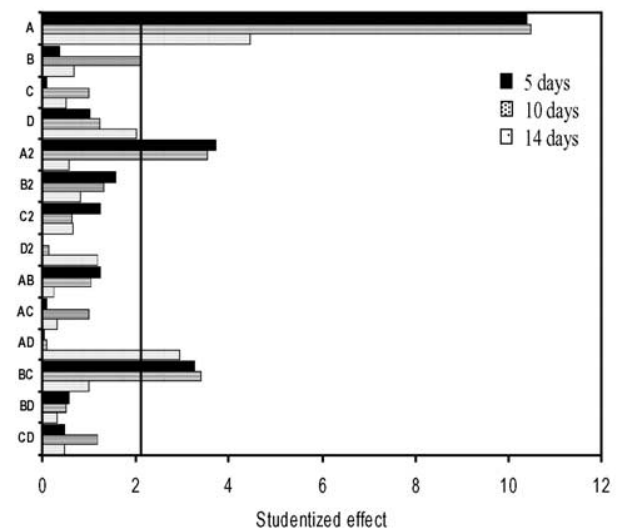

(b)

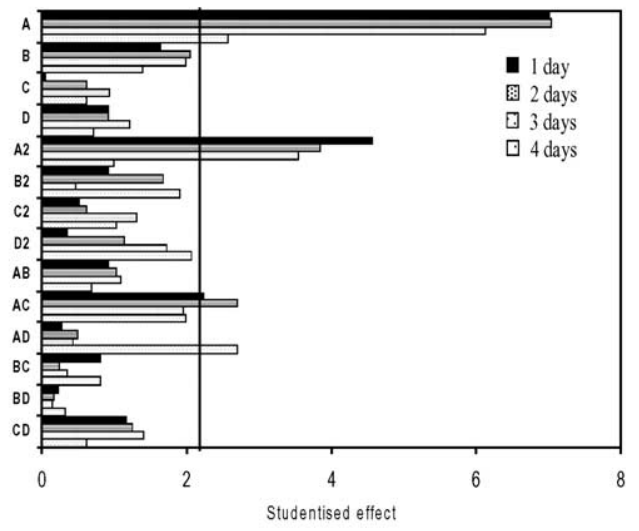

(d)

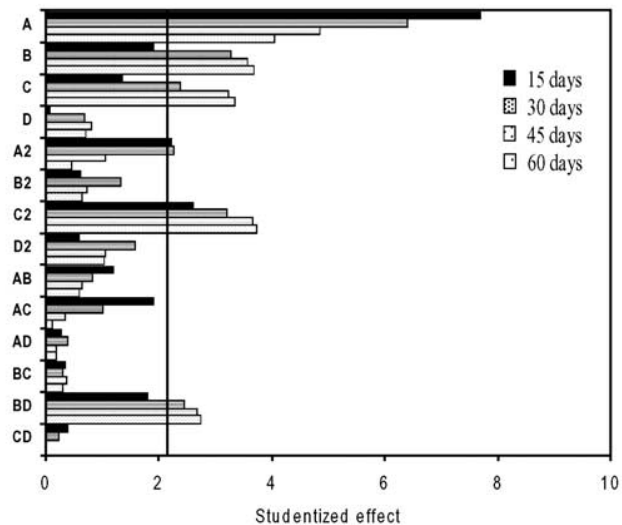

Fig. 4. Studentized effects on vitamin $\mathrm{C}$ retention at (a) +5 , (b) -6 , (c) -12 and (d) $-18^{\circ} \mathrm{C}$. A-initial temperature $\left(T_{0}\right)$; B-surface heat transfer coefficient $(h)$; C-packaging thermal conductivity $\left(\lambda_{\mathrm{p}}\right)$; and $\mathrm{D}$-packaging thickness $\left(x_{\mathrm{p}}\right)$.

temperature: (i) low activation energies (ascorbic acid and total vitamin $\mathrm{C}$ ), and (ii) high activation energies (colour and flavour)

\section{Ascorbic acid and total vitamin C}

Ascorbic acid auto-oxidation is not a temperature sensitive reaction (low $E a$ ), because of the high mobility of the molecular oxygen. The studied $(\mathbf{A}, \mathbf{B}, \mathbf{C}$ and $\mathbf{D})$ factors: respectively initial temperature, $T_{0}$, surface heat transfer coefficient inside the refrigerator, $h$, and packaging materials (thermal conductivity, $\lambda_{\mathrm{p}}$, and thickness, $x_{\mathrm{p}}$ ), have significant studentized effects on AA retention at $+5^{\circ} \mathrm{C}$. Important interactions exist between the packaging thermal conductivity and packaging thickness, mainly because these are responsible for thermal resistance. Fig. 3 presents the studentized effects of $T_{0}, h, \lambda_{\mathrm{p}}$ and $x_{\mathrm{p}}$ on ascorbic acid retention, at different home storage temperatures. Below the freezing point, AA retention is strongly influenced by the initial temperature, $T_{0}$.

The effect of thermal insulation $\left(\lambda_{\mathrm{p}}\right.$ and $\left.x_{\mathrm{p}}\right)$ is more significant also at the initial stages, when the temperature gradients inside the green beans package are greater at the higher temperatures (e.g. +5 and $-6{ }^{\circ} \mathrm{C}$ ). Packaging materials become less important at the lower storage temperatures $\left(-12\right.$ and $\left.-18^{\circ} \mathrm{C}\right)$, as the temperature inside the package tends to oscillate with the same frequency of the thermal cycles.

Total vitamin $\mathrm{C}$ retention is also highly influenced by all the studied factors (Fig. 4). The surface heat transfer coefficient inside the refrigerator and its interactions between the packaging material/thickness are statistically significant, especially at $+5{ }^{\circ} \mathrm{C}$. The statistical significance of $h, \lambda_{\mathrm{p}}$ and $x_{\mathrm{p}}$ decreases for lower storage temperatures.

Factor effects tend to non-significant levels as storage time increases and vitamin $\mathrm{C}$ retention tends to residual levels. Bellow the $-6{ }^{\circ} \mathrm{C}$, the initial temperature is a very significant factor.

\section{Flavour and total colour difference}

All the studied factors produce significant effects in terms of colour and flavour (Figs. 5 and 6, respectively). Nevertheless, as colour and flavour degradation kinetics are 
(a)

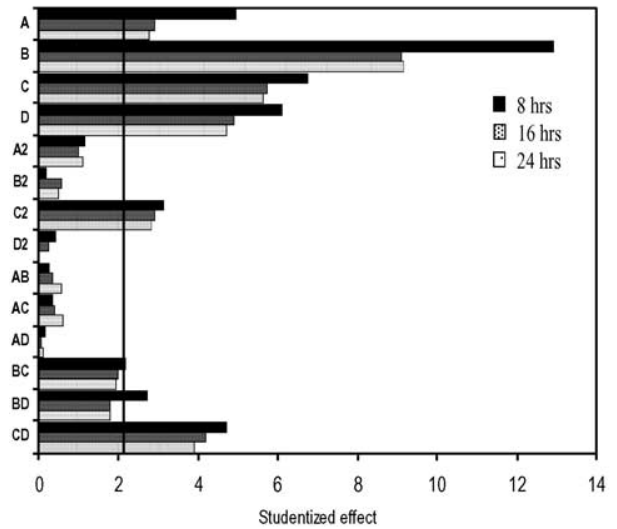

(c)

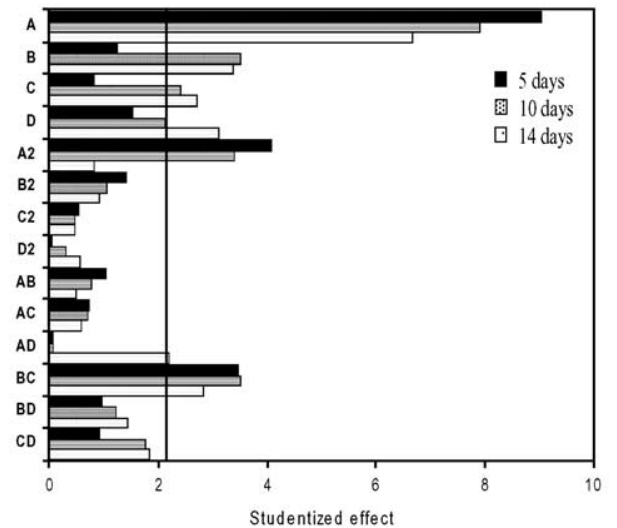

(b)

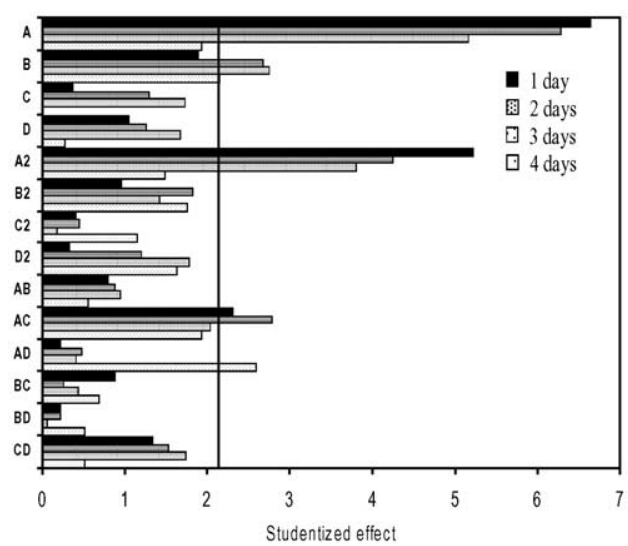

(d)

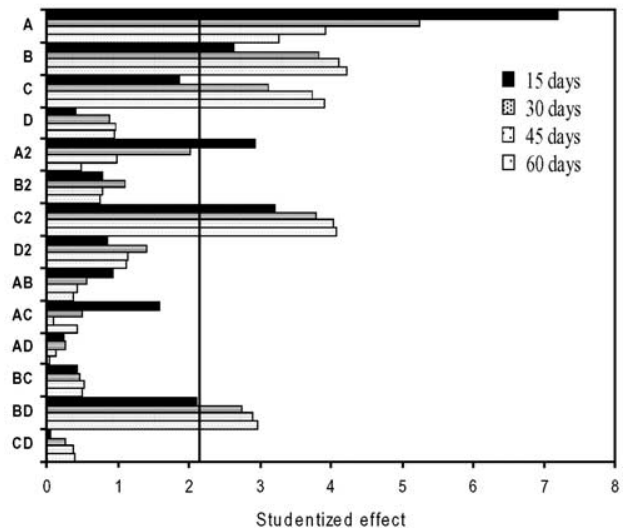

Fig. 5. Studentized effects on $\mathrm{TCD}_{\mathrm{H}}$ increase at $(\mathrm{a})+5$, (b) -6 , (c) -12 and $(\mathrm{d})-18{ }^{\circ} \mathrm{C}$. A-initial temperature $\left(T_{0}\right)$; B-surface heat transfer coefficient $(h)$; $\mathrm{C}$-packaging thermal conductivity $\left(\lambda_{\mathrm{p}}\right)$; and $\mathrm{D}$-packaging thickness $\left(x_{\mathrm{p}}\right)$.

more temperature sensitive (higher $E a$ ) than AA and total vitamin $\mathrm{C}$ degradation, a different pattern in factor analysis is obtained.

Flavour and $\mathrm{TCD}_{\mathrm{H}}$ are highly influenced by the surface heat transfer coefficient (factor $\mathrm{B}$ ) inside the refrigerator and the packaging material (factors $\mathrm{C}$ and $\mathrm{D}$ ), especially at $+5{ }^{\circ} \mathrm{C}$. Quality loss kinetics with a high $E a$, such as $\mathrm{TCD}_{\mathrm{H}}$ and flavour, are more influenced by the thermal protection offered by the packaging material and refrigeration conditions, than low Ea quality loss kinetics, such as AA and total vitamin C (Figs. 3 and 4, respectively).

The studied factors are extremely important to model green beans quality loss throughout storage. The studentized effects have distinct patterns for quality loss reactions with high and low Arrhenius activation energy. High activation energy quality loss reactions, such as flavour and colour degradation, are highly influenced by temperature. Thus, thermal insulation, provided by the packaging material, is an important factor to maintain low temperatures during short periods of time, such as temperature abuses. The best/worst insulation cases, presented in Fig. 2(a)-(d), respectively, are good examples of the thermal insulation effect on the spectrum of temperature responses.

Quality loss reactions with low $E a^{\prime}$ s, such as AA autooxidation, DHAA oxidation and starch hydrolysis (see Table 2), are not as much influenced by the use of good thermal insulation materials or low storage temperatures, compared with flavour and colour. However, thermal insulating is yet the only way to provide thermal protection against temperature cycles inside refrigerators and temperature abuses.

\section{Quality retention analysis}

The response surface design maximum and minimum limits (Table 3) set a wide range of packaging materials and storage conditions inside refrigerators, at the different storage temperatures. Such differences, however, do not produce extreme differences in terms of quality retention. For example, for all studied temperatures, the maximum retention at the end 
(a)

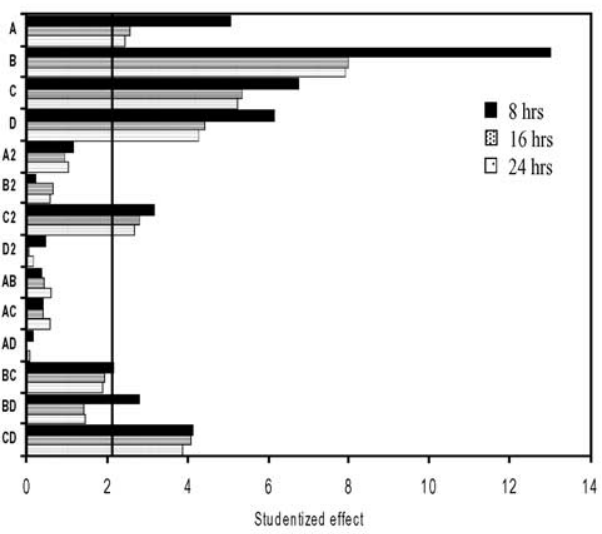

(c)

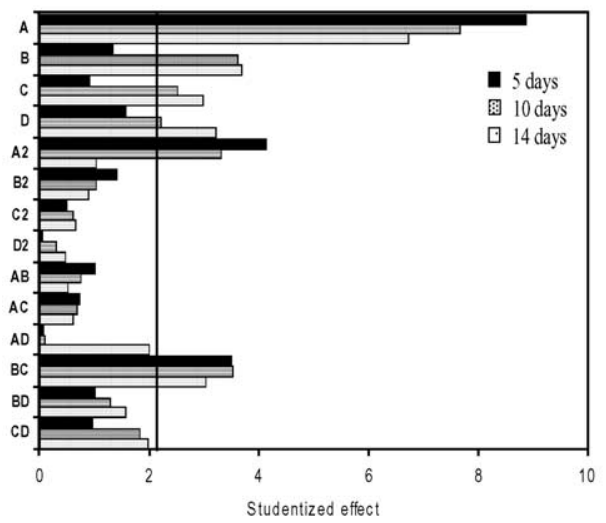

(b)

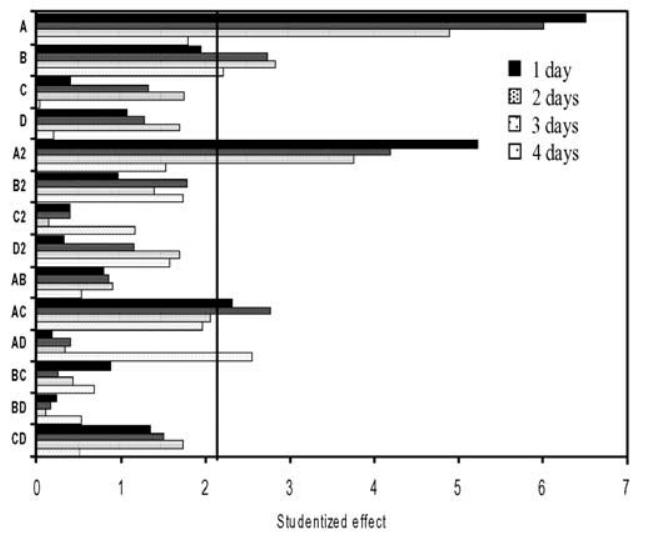

(d)

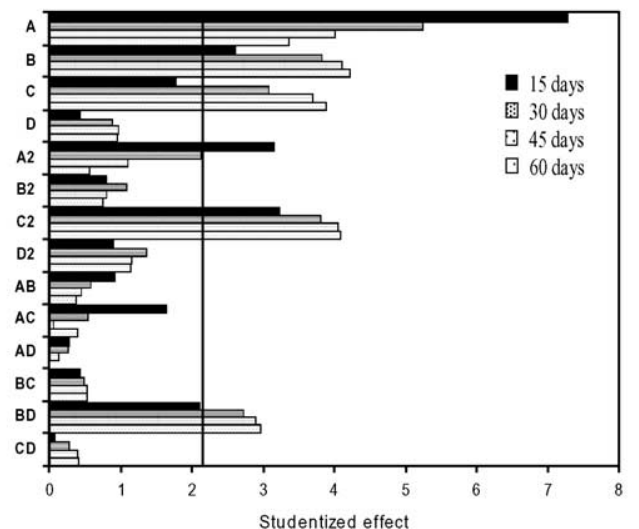

Fig. 6. Studentized effects on flavour retention at (a) +5 , (b) -6 , (c) -12 and (d) $-18{ }^{\circ} \mathrm{C}$. A-initial temperature $\left(T_{0}\right)$; B-surface heat transfer coefficient $(h)$; C-packaging thermal conductivity $\left(\lambda_{\mathrm{p}}\right)$; and D—packaging thickness $\left(x_{\mathrm{p}}\right)$.

of the shelf life date (Table 1), for all the studied quality parameters, is obtained at the factor combinations: $T_{0}=$ $-17.5^{\circ} \mathrm{C}, h=9 \mathrm{~W} \mathrm{~m}^{-2} \mathrm{~K}^{-1}, \lambda_{\mathrm{p}}=0.02 \mathrm{~W} \mathrm{~m}^{-1} \mathrm{~K}^{-1}$ and $x_{\mathrm{p}}=0.003 \mathrm{~m}$, where the maximum thermal isolation is achieved. Minimum quality retention is always obtained at the lowest thermal isolation case, when: $T_{0}=-17.5^{\circ} \mathrm{C}, h=$ $12 \mathrm{~W} \mathrm{~m}^{-2} \mathrm{~K}^{-1}, \lambda_{\mathrm{p}}=0.085 \mathrm{~W} \mathrm{~m}^{-1} \mathrm{~K}^{-1}$ and $x_{\mathrm{p}}=0.0002 \mathrm{~m}$.

Results dispersion between maximum and minimum values are higher at $+5{ }^{\circ} \mathrm{C}$, where thermal isolation is a very important factor. For example, flavour retention presents the highest variation within the studied factor limits. The difference between maximum and minimum limits attained 12.21 and $5.45 \%$, respectively, after 8 and $24 \mathrm{~h}$ of storage. $\mathrm{TCD}_{\mathrm{H}}$ differences are also significant at $+5{ }^{\circ} \mathrm{C}$, where differences between maximum and minimum limits are 1.45 and $2.67 \%$, respectively after 8 and $24 \mathrm{~h}$ of storage. Such results reassure the significance of thermal-insulation factors, in protecting frozen foods quality parameters with high $E a^{\prime} \mathrm{s}$, at high storage temperatures.

Flavour and $\mathrm{TCD}_{\mathrm{H}}$ differences between maximum and minimum limits are not very significant at temperatures below
$+5{ }^{\circ} \mathrm{C}$, where results dispersion range is generally less than $1 \%$. The retention of quality parameters with low activation energies (AA and total vitamin $\mathrm{C}$ ) does not exhibit very significant differences within the factors space $(<1 \%)$.

The differences in quality retention between maximum and minimum thermal insulation cases decrease with storage time and low storage temperature, for all the studied parameters.

\section{Conclusions}

Frozen green beans quality losses at low temperatures is a complex problem, where the many variables and mechanistic phenomena were taken into consideration. The developed model was a first approach to mathematically describe the quality losses mechanisms, and to study how packaging insulation and home storage conditions affect quality losses. The volume of information, necessary to build the simulation system, makes the model complete enough to simulate quality losses throughout storage. 
Simulation showed that the different packaging materials and surface heat transfer coefficient inside the refrigerator are significant factors against temperature oscillations, especially at high temperatures $\left(+5^{\circ} \mathrm{C}\right)$. The packaging materials protection is not as significant at lower temperatures (e.g. -12 and $-18{ }^{\circ} \mathrm{C}$ ), where temperature oscillations inside package almost follows the refrigeration cycles.

Temperature cycles inside refrigerators are relevant to quality losses. Thermal cycles are detrimental at the higher storage temperatures, despite the short periods of storage at +5 and $-6{ }^{\circ} \mathrm{C}$. Temperature cycles have a long term effect at lower temperatures, such as at -12 and $-18{ }^{\circ} \mathrm{C}$. As more time is spent at temperatures below the set-point at low temperature, quality retention is higher than the expected at a constant set-point temperature.

Quality parameters, such as flavour and colour, with high $E a^{\prime}$ s (which are more sensitive to temperature) are very susceptible to the thermal fluctuations at +5 and $-6{ }^{\circ} \mathrm{C}$, and better preserved at the lower temperatures. Quality parameters with low $E a^{\prime}$ s are not as sensitive to thermal cycles at high storage temperatures, but are less preserved at the lower storage temperatures, such as ascorbic acid and total vitamin C. Thermal cycles have, however, a lower impact on quality retention than the rest of the studied factors, such as the storage temperature and initial temperature.

Green beans quality losses during frozen storage has proved to be mostly influenced by temperature and kinetic properties. Quality losses convergence (i.e. low dispersion in results) occurs almost at any of the studied storage temperatures. Longer storage times also increases the convergence, because quality tends to its residual value.

Such emergent simplicity of food systems, under frozen storage, makes the use of isothermal storage data a reasonable method to produce shelf-life dates, under controlled temperature inside refrigerators. Thus, more sophisticated shelf-life dating systems can be presented to the consumer, such as high quality life dates or predicted nutritional and sensory value for different storage periods.

Packaging thermal insulating materials are important at the higher storage temperatures. These are a protection against temperatures abuses that occur throughout the distribution chain. Simulations show that, adequate thermal insulation is a key factor to maintain low temperatures, when green beans packages are exposed above the freezing point.

Simulations also demonstrate that the star marking system is a well-designed dating system to produce 'after sale' dates. This system fails to account for the temperature history and possible temperature abuses, that occurred previously, throughout the distribution chain. Under these circumstances, the star marking system is optimistic in terms of absolute quality retention values.

\section{Acknowledgements}

The author R.C. Martins, gratefully acknowledges his PhD grant, PRAXIS XXI BD/18541/98, to the Fundação para a Ciência e Tecnologia (FCT).

\section{References}

[1] R.C. Martins, C.L.M. Silva, Modelling colour and chlorophyll's losses of frozen green beans (Phaseolus vulgaris L.), Int J Refrigeration 25 (2002) 987-995.

[2] R.C. Martins, C.L.M. Silva, Kinetics of frozen stored green beans (Phaseolus vulgaris L.) quality changes: texture, vitamin $C$, reducing sugars and starch, J Food Sci 68 (7) (2003) 2232-2237.

[3] W.C. Dietrich, F.E. Lindquist, J.C. Miers, G.S. Bohart, H.J. Newman, W.F. Talburn, The time temperature tolerance of frozen foods. iv. Objective tests to measure adverse changes in frozen vegetables, Food Technol 10 (1956) 109-113.

[4] M.M. Boogs, W.C. Dietrich, M.D. Nutting, R.L. Olson, F.E. Lindquist, G.S. Bohart, H.J. Neumann, H.J. Morris, Timetemperature tolerance of frozen foods. xxi. Frozen peas, Food Technol 14 (1960) 181-185

[5] W.C. Dietrich, M.M. Boogs, M.D. Nutting, N.E. Weinstein, Time temperature tolerance of frozen foods. xxiv. Quality changes in cauliflower, Food Technol 14 (1960) 123-128.

[6] W.B. Van Arsdel, The time tolerance of frozen foods. i. Introduction-the problem and the attack, Food Technol (1957) 28-33.

[7] W.D. Van Arsdel, D.G. Guadagni, Time-temperature tolerance of frozen foods. Xv. Method of using temperature histories to estimate changes in frozen food quality, Food Technol (1959) 14-19.

[8] Martins RC. Modelling temperature abuses to frozen foods and effects on quality. PhD Thesis, Escola Superior de Biotecnologia, Universidade Católica Portuguesa, Porto, Portugal; 2004.

[9] D. Braess, Finite elements. Theory, fast solvers, and applications in solid mechanics, Cambridge University Press, Cambridge, 1997.

[10] L.J. Segerlind, Applied finite element analysis, 2nd ed., Macmillan Press, Ltd, New York, 1984.

[11] R.G. Brown, The beowulf design, Cots parallel clusters and supercomputers, 2000, http://www.phy.duke.edu/ rgb/ beowulf_advanced.ps.

[12] R.G. Brown, Engineering a beowulf-style computer cluster, 2000, http://www.phy.duke.edu/ rgb/beowulf_book.ps.

[13] M.G. Almeida, R.C. Martins, Installation of a beowulf class cluster over linux mandrake 7.1, 2001, http://biotec.serveftp. org/.

[14] G.A. Geist, A. Beguelin, J.J. Dongarra, W. Jiang, R. Manchek, V. Sunderam, PVM: parallel virtual machine, A user's guide and tutorial for networked parallel computing, The MIT Press, Cambridge, Massachusetts, 1994, http://www.netlib.org/ pvm3/book/pvm-book.ps.

[15] H.S. Ramaswamy, M.A. Tung, Thermo-physical properties of apples in relation to freezing, J Food Sci 46 (1981) 724-728.

[16] H.G. Schwartzberg, Effective heat capacities for freezing and thawing of food, J Food Sci 41 (1976) 153. 
[17] R. Villota, J.G. Hawkes, Reaction kinetics in food systems, In Handbook of Food Engineering, Marcel Dekker, New York, 1992, p. 39-144.

[18] H. Tong, Non-linear time series: a dynamical system approach, Oxford University Press, New York, 1994.

[19] T.P. Labuza, Shelf-life dating of foods, Food and Nutrition Press, Wesport, Connecticut, 1982.
[20] D.C. Montegomery, Design and analysis of experiments, 3rd ed., Wiley, Singapore, 1991.

[21] Stat-Ease. Design-Expert, version 4.0.2. Stat-Ease, Inc.; 1994.

[22] R.C. Martins, C.L.M. Silva, Computational design of accelerated life testing of frozen foods, J Food Engng 64 (4) (2004) 455-464. 